\title{
DIE TIPERING VAN VERBRUIKERSLEWENSTYLE
}

\section{R. DU PREEZ}

\section{J.B. DU TOIT}

Departement Bedryfsielkunde

Universiteit van Stellenbosch

\begin{abstract}
The typifying of consumer lifestyles. Due to the lack of a South-African instrument to measure consumer lifestyles, a questionnaire is constructed from which lifestyle typifications can be made. This instrument is constructed with reported research as a basis, as well as new items written with the purpose of this research project in mind. In this study four lifestyle typifications are constructed namely (a) the apathetic group, (b) the artistic, socially uninvolved bookworm, (c) the politically active, socially integrated group and (d) the first-class group. Recommendations for future research are made.
\end{abstract}

\section{OPSOMMING}

Weens die gebrek aan 'n Suid-Afrikaanse meetinstrument om verbruikerslewenstyle te meet, is ' $n$ vraelys ontwikkel waaruit lewenstyltiperings gedoen kan word. Hierdie instrument is ontwikkel vanuit gerapporteerde navorsing en nuwe items wat geskryf is vir die doeleindes van hierdie navorsing. In hierdie studie is vier lewenstyltiperings saamgestel, naamlik (a) die apatiese groep, (b) die kunssinnige, sosiaal-onbetrokke boekwurms, (c) die polities-aktiewe, sosiaal-geïntegreerdes en (d) die voortreflikes. Aanbevelings vir toekomstige navorsing word gemaak.

Lewenstyl word in die literatuur omskryf as 'n oorkoepelende begrip wat ' $n$ individu se aktiwiteite, belangstellings, waardes, opinies, houdings, familiebetrekkinge, kultuur, demografie, sosiale klas en persoonlikheid insluit (Fox, 1989). Hiérdie komponente van lewenstyl kan in 'n lewenstylkomponent-model soos skematies in Figuur 1 uiteengesit, saamgevat word.

\begin{tabular}{|l|l|}
\multicolumn{2}{c}{ LEWENSTYL } \\
\cline { 2 - 2 } \multicolumn{1}{c|}{} \\
AKTIWITEITE & \\
BELANGSTELLINGS & \\
DEMOGRAFIE & BEHOEFTES EN MOTIEWE \\
SOSIALE KLAS & WAARDES \\
FAMILIE & PERSOONLIKHEID \\
\hline
\end{tabular}

WAARNEEMBAAR

\section{NIE-DIREK-WAARNEEMBAAR NIE}

Figuur 1: Lewenstylkomponent-model (Fox, 1989, p. 81)

Die Social Research Institute (SRI) is 'n leier op die gebied van lewenstylnavorsing in die VSA. Die nege lewenstyle van Mitchell (1984) het uit hierdie navorsing ontstaan. Dié lewenstyltipologie is ontwikkel vanuit die VALS (Values en Lifestyles) vraelys wat grootliks gebaseer is op die behoeftehiërargie van Maslow en die konsep van sosiale persoonlikheid ("social character"). Die konsep sosiale persoonlikheid word deur Riesman (in Zinkman en Shermohamad, 1986) in drie klasse verdeel, naamlik tradisioneel-gerig, self-gesentreerd en ander-gesentreerd. Die VALS vraelys bestaan uit gemiddeld 34 vrae (Holman in Kahle, Beatty en Homer, 1986, rapporteer 36 items en Mitchell in Kahle, Beatty en Homer, 1986 rapporteer 32 items) wat persone klassifiseer in een van die nege lewenstylgroepe. Elk van hierdie groepe is omskryf

Versoeke vir afdrukke moet gerig word aan R. du Preez (Fox), Departement Bedryfsielkunde, Universiteit van Stellenbosch, Stellenbosch 7600 . na aanleiding van hul onderskeie waardes, motiewe, gelowe, behoeftes, drome, en menings. Die nege lewenstylgroepe is onderverdeel in vier hoofgroepe naamlik diegene gedryf deur behoeftes ("need-driven"), ander-gesentreerdes ("outer-directed"), self-gesentreerdes ("inner-directed") en geïntegreerdes ("integrated") (Mitchell, 1984).

Op die terrein van lewenstylnavorsing kom die navorsing van Kahle, Beatty \& Homer (1986) sterk na vore. Hierdie navorsers ontwikkel die LOV (List of Values) om waardes van individue te meet en te tipeer met behulp van 'n "empiriese spieëlingstegniek". Hiérdie tegniek behels die beraming van benaderde gewigte van vraelysitems. Hierdie ontwikkeling is genoodsaak deur die ongeneëndheid van SRI-Internasionaal om voldoende inligting oor die verswaringsalgoritmes en die ontwikkeling van VALS, wat hieruit voortspruit, te publiseer.

Weens die gebrek aan 'n lewenstylinstrument in Suid-Afrika is ' $n$ behoefte geïdentifiseer om ' $n$ lewenstylvraelys met aanvaarbare psigometriese eienskappe en klassifikasievermoë te ontwikkel. Verskeie kommersiële produkte soos byvoorbeeld die 4C's van Young en Rubicam en Marketing Research Africa se Sociomonitor is in Suid-Afrika beskikbaar, maar hiérdie meetinstrumente word nie algemeen beskikbaar gestel nie. Die beskouing van lewenstyl in bogenoemde navorsing verskil ook van die reeds gedefinieerde begrip, van lewenstyl.

Die doelstelling van hierdie studie was dus die ontwikkeling van 'n Suid-Afrikaanse lewenstylvraelys om tiperings van verbruikerslewenstyle te kan doen.

\section{METODE}

\section{Navorsingstrategie}

Weens die gebrek aan navorsing op hierdie terrein is van bevestigende sowel as eksploratiewe navorsingstrategieë gebruik gemaak.

Die prosedure voorgestel deur Churchill (1979) gee 'n duidelik uiteensetting van die ontwikkeling van meetinstrumente en is in die ontwikkeling van die lewenstylvraelys nagevolg. Churchill (1979) se prosedure voldoen ook aan gestelde standaarde vir 'n wetenskaplike navorsingstrategie. Die prosedure kan soos volg skematies in Figuur 2 voorgestel word: 


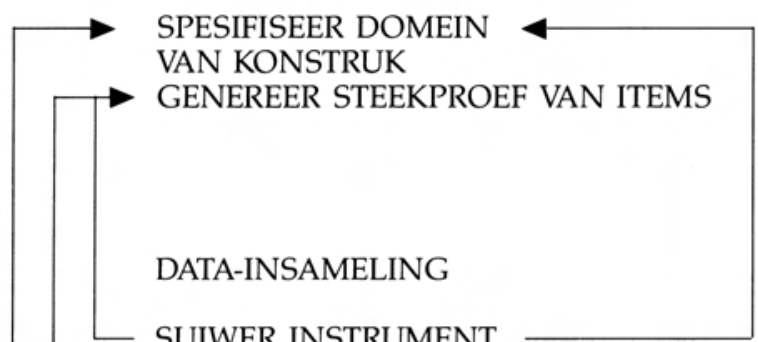

SUIWER INSTRUMENT

DATA-INSAMELING

BEPAAL BETROUBAARHEID

BEPAAL GELDIGHEID

ONTWIKKEL NORMS
LITERATUURSOEKTOG

LITERATUURSOEKTOG FOKUSGROEPE

OPNAMES

KRITIEKE INSIDENTE

KOËFFISIËNT-ALFA

FAKTORONTLEDING

KOËFFISIËNT-ALFA

VERDEELDE HELFTE-BETROUBAARHEID MULTIDIMENSIE-MULTISTAP MATRIKS KRITERIUMGELDIGHEID VERSPREIDING STATISTIEKE

Figuur 2: Voorgestelde prosedure vir die ontwikkeling van meetinstrumente (Churchill, 1979, p. 66)

\section{Die meetinstrument}

(i) Die daarstelling van ' $n$ itempoel

Weens die gebrek aan gepubliseerde lewenstylnavorsing in Suid-Afrika is ' $n$ itempoel saamgestel vanuit gerapporteerde vraelyste en items wat spesiaal vir die doeleindes van hierdie vraelysontwikkeling geskryf is (Wells \& Tigert, 1971; Kahle, Beatty \& Homer, 1986; Roberts \& Wortzel, 1979; Boote, 1981; Kinnear \& Taylor, 1976; Beatty, Homer \& Kahle, 1987; Mehrotra en Wells, 1977; Wells, 1975; Burns en Harrison, 1979; Tigert, Lathrope \& Bleeg, 1971; Douglas \& Urban, 1977; Wells, 1985; Bruce, 1988). Elke item is gekoppel aan 'n 7-punt Likertskaal waarop individue hul mate van ooreenstemming of verskille kon aandui. Al die items is verteenwoordigend van die geïdentifiseerde komponente van lewenstyl naamlik aktiwiteite, belangstellings, opinies, die familie, lys van waardes (LOV), en items vanuit die nege Amerikaanse lewenstyle en mediagewoontes. Dit is noodsaaklik geag om 'n persoonlikheidsdimensie in die studie in te sluit vanweë die duidelike klem wat in die literatuur op persoonlikheid geplaas word. Riesman se Inner-Other Social Preference Scale is in sy oorspronklike vorm gebruik (Kassarjian, 1962).

\section{(ii) Vraelys-voorstudie}

Die totale vraelys bestaande uit (1) die Inner-Other Social Preference Scale en (2) die ander subskale soos aangedui in Tabel 1 is onderwerp aan ' $n$ voorstudie $(n=249)$ waarna die verkreë data aan frekwensie-ontleding en itemontleding onderwerp is. Koëffisiënt-alfa is bereken vir afsonderlike items asook vir item-totale. Die voorstudie-betroubaarheid van die Inner-Other Social Preference Scale was hoogs onbevredigend $(\mathrm{rtt}=0,5403)$, in vergelyking met betroubaarhede van 0,32 tot 0,94 wat in die literatuur gerapporteer word (Kassarjian, 1962, p. 217). In die lig hiervan is besluit om die vraelys weer in sy geheel in die hoofstudie te gebruik ten einde die betroubaarheid daarvan by ' $n$ ander groep te bepaal. $\mathrm{Na}$ ' $n$ itemontleding van die totale vraelys is 'n finale vraelys bestaande uit 135 items (wat verteenwoordigend is van die verskillende geïdentifiseerde dimensies van lewenstyl) gekonstrueer vir gebruik in die hoofstudie.

(iii) Betroubaarheidsbepaling in hoofstudie

Die betroubaarheid van die saamgestelde vraelys word soos volg in Tabel 1 aangedui.
TABEL 1

HOOFSTUDIE-BETROUBAARHEIDSBEPALINGS

SUBSKAAL KOËFFISIËNT-ALFA AANTAL ITEMS

\begin{tabular}{lcr}
\hline Aktiwiteite & 0,7151 & 19 \\
Belangstelling & 0,7430 & 25 \\
Opinie & 0,6792 & 6 \\
Familie & 0,8068 & 7 \\
Lys van & & \\
Waardes & 0,7359 & 12 \\
Nege Ameri- & & \\
kaanse lewen- & & \\
style & 0,7531 & 15 \\
Media & 0,7314 & 15 \\
IOSP-skaal & 0,6637 & 36 \\
\hline
\end{tabular}

Riesman se Inner-Other Social Preference Scale toon 'n koëffisiënt-alfa van 0,6637 wat beter is as die 0,5403 wat in die voorstudie verkry is. Koëffisiënt-alfa vir die totale vraelys is 0,8483 .

\section{Proefpersone}

Die universum is gespesifiseer as alle voltydse binnemuurse studente aan die Universiteit van Stellenbosch woonagtig te Stellenbosch gedurende die akademiese jaar. Steekproefneming met terugplasing het ewekansig plaasgevind en gevolglik is 'n steekproef van 600 uit verskillende jaargroepe en fakulteite getrek. 'n Vraelys-responskoers van $85 \%$ is behaal waarvan $65 \%$ bruikbaar was vir ontleding. Hierdie bruikbare response verteenwoordig 390 vraelyste $(n=390)$.

\section{Ontledingstegnieke}

Statistiese verwerkings is gedoen met behulp van die SPSS$X(2.0)$, SAS (5.0) en BMDP (1985) pakkette. 'n Kombinasie van die drie pakkette is genoodsaak weens die onvermoë van een pakket om al die verwerkings te doen.

Die datastel is onderwerp aan hoofkomponentanalise met varimax rotasie om enige onderliggende struktuur bloot te lê. 
Trosanalise is gedoen om relatief homogene onderling uitsluitende groepe individue te identifiseer. Hierdie ontleding is op verskeie maniere toegepas naamlik:

(i) Trosanalise met al 135 veranderlikes;

(ii) Trosanalise met "nuwe" saamgestelde veranderlikes. Hierdie veranderlikes is verkry deur die verskillende items in 'n betrokke sub-skaal te sommeer om 'n "nuwe" veranderlike te skep;

(iii) Trosanalise met al die veranderlikes wat bo 0,3 en onder $-0,3$ laai op die hoofkomponentontleding;

(iv) Trosanalise met die hoofkomponenttellings van elk van die proefpersone.

\section{RESULTATE EN GEVOLGTREKKINGS}

Hoofkomponentontleding dui op 10 hoofkomponente wat $34,30 \%$ van die variansie verklaar. Hierdie resultaat is as onbevredigend beskou vanweë die klein hoeveelheid variansie wat verklaar word deur die groot aantal hoofkomponente.

Trosanalise met 96 veranderlikes wat laai op die hoofkomponente (bo 0,30 en onder -0,30) en wat beduidend is op die $1 \%$ peil dui op vier lewenstylgroeperings. Die tiperings van die groepe is grootliks gebaseer op die gemiddelde waardes van die 96 veranderlikes. Hierdie gemiddeldes moet nie as entiteite beskou word nie, maar in konteks met die ander groepe se gemiddeldes gesien word. Hierdie groeperings kan soos volg ruimtelik voorgestel word;

\section{GEVALLE MET POSITIEWE GEWIGTE}

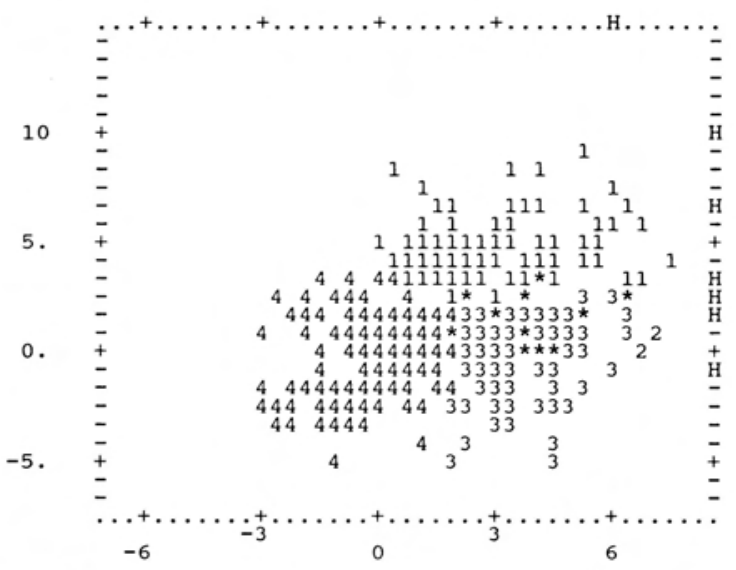

VLAK DEUR DIE MIDDELPUNT VAN TROSSE

\section{FIGUUR 3: Ruimtelike voorstelling van die vier groeperings van individue}

Uit die resultate was dit moontlik om vier duidelik onderskeibare verbruikerslewenstyle naamlik (1) die apatiese groep, (2) die kunssinnige, sosiaal-onbetrokke boekwurms, (3) die polities-aktiewe, sosiaal-geïntegreerdes en (4) die voortreflikes saam te stel. Die tipering van hierdie vier lewenstylgroepe word in Tabel 2 weergegee.

\section{DIE TIPERING VAN VERBRUIKERSLEWENSTYLE}

\begin{tabular}{|c|c|c|}
\hline & $\begin{array}{l}\text { GROEPERING 1: DIE } \\
\text { APATIESE GROEP }(\mathrm{n}=90)\end{array}$ & $\begin{array}{l}\text { GROEPERING 2: DIE } \\
\text { KUNSSINNIGE, SOSIAAL- } \\
\text { ONBETROKKE BOEK- } \\
\text { WURM }(\mathrm{n}=14)\end{array}$ \\
\hline $\begin{array}{l}\text { Aktiwiteite en } \\
\text { Belangstellings: }\end{array}$ & $\begin{array}{l}\text { * 'n Matige en sosiale be- } \\
\text { langstelling in sport en } \\
\text { stokperdjies. } \\
\text { * Min of geen belangstelling } \\
\text { in kuns-, ballet- en } \\
\text { teateruitvoerings. } \\
\text { * Inkopies is 'n vervelige } \\
\text { noodsaaklikheid en voort- } \\
\text { spruitend hieruit 'n onver- } \\
\text { moë om te begroot vir } \\
\text { inkopies, weerstand teen } \\
\text { die vergelyking van pryse } \\
\text { en die versameling van af- } \\
\text { slagkoepons. } \\
\text { * Polities onaktief. } \\
\text { * Gemeenskapsaktiwiteite en } \\
\text { liefdadigheidswerk word } \\
\text { soms aangepak. }\end{array}$ & $\begin{array}{l}\text { * Min of geen belangstelling } \\
\text { in sport. } \\
\text { * Spansport verskaf geen } \\
\text { bevrediging nie. } \\
\text { * Besoek graag teater-, ballet- } \\
\text { en kunsuitvoerings. } \\
\text { * Geniet dit baie om inko- } \\
\text { pies te doen, maar dit } \\
\text { geskied sonder 'n formele } \\
\text { begroting. Geen gebruik } \\
\text { word van afslagkoepons } \\
\text { gemaak nie en pryse word } \\
\text { baie selde met mekaar } \\
\text { vergelyk. Spesiale aan- } \\
\text { biedinge sal ook net soms } \\
\text { die aandag van lede trek. } \\
\text { * Polities onaktief. }\end{array}$ \\
\hline
\end{tabular}

GROEPERING 3: POLITIES

AKTIEWE, SOSIAAL-GEÏN

TEGREERDES $(\mathrm{n}=127)$

* Sport word matig beoefen.

* Ballet-, teater- en kunsuitvoerings word graag besoek en word as goeie vermaak beskou.

* Redelik aktief wat inkopies betref, maar begroot nie altyd daarvoor nie. Soek soms winskopies, maar maak nie gebruik van afslagkoepons nie. Die vergelyking van pryse vind wel plaas.

* Individue is polities aktief. Stel baie belang in die politieke spel en vind die politiek oor die algemeen interessant.

* Vriende en die sosiale interaksie met hulle is van belang.

$\begin{array}{ll}\text { Opinies: } & \text { * Optimisties oor Suid-Afrika } \\ & \text { se toekoms. } \\ & \text { Positief teenoor veran- } \\ & \text { dering. }\end{array}$

Familiebetrekkinge:

\footnotetext{
* Mees skeptiese mening oor Suid-Afrika se toekoms. * Veranderinge word met 'n oop gemoed benader.
}

\section{* Optimisties oor Suid-Afrika se toekoms.}

\footnotetext{
* Totaal onbetrokke by enige familiesituasie. Hulle geniet nie familiebyeenkomste nie en ook nie familieaktiwiteite nie. Ondersteuning van ouers is nie aanwesig nie en daarmee saam is daar geen noue bande tussen die onder-

* Familiebetrekkinge is baie sterker as by die twee voorafgaande groeperings. * Gesinsband, ouerbelangstelling en ouertrots is baie sterk aanwesig.

* Gesinslewe as die basis van die gemeenskap word hoog aangeslaan.
} skeie lede nie. Gesinslewe word ook in 'n skeptiese lig gesien as die basis van die gemeenskap.
GROEPERING 4: DIE VOORTREFLIKES $(\mathrm{n}=159)$

*'n Baie sterk belangstelling in sport is aanwesig en hulle is gevolglik baie aktief op hierdie gebied.

* Spansport verskaf baie bevrediging.

* Die kunste en teater word soms besoek en is deel van 'n breë belangstellingsveld.

* Aankope word nugter benader met 'n begroting. Aandag word gegee aan spesiale aanbiedinge en prysvergelykings. Winskopies en afslag koepons word ook gebruik.

* Politiek interesseer hierdie persone tot 'n mate, maar hulle kan nie as polities aktief beskou word nie.

* Sosiaal aangepas en geniet die samesyn met vriende. Intieme verhoudinge met ander word as baie belangrik beskou.

* Veranderinge word nie skepties waargeneem nie en 'n oopheid jeens verandering is waarneembaar.

* 'n Sterk optimisme heers oor Suid-Afrika se toekoms.

${ }^{*}$ Kenmerkend is die sterkte van die familiebande. Hul ouers stel belang in hulle prestasies en gee ondersteuning.

* Die gesin word beskou as die mees belangrike basis van die gemeenskap. 
GROEPERING 1: DIE

APATIESE GROEP $(\mathrm{n}=90)$
GROEPERING 2: DIE

KUNSSINNIGE, SOSIAAL-

ONBETROKKE, BOEK-

WURM $(\mathrm{n}=14)$
GROEPERING 3: POLITIES-

AKTIEWE, SOSIAAL-GEIIN-

TEGREERDES $(\mathrm{n}=127)$
GROEPERING 4: DIE

VOORTREFLIKES $(\mathrm{n}=159)$
Waardes en lewenswyse:

* Waarde word geheg aan finansiële sekuriteit en 'n gevoel van veiligheid. * Kenmerkend is die minder sterk selfverwesenlikingsdrang, doelbereikingstrewe en die strewe na die afdwing van respek.

* Ambisies is nie 'n dryfkrag nie. Die relatiewe gebrek aan die strewe na sterk individuele ontwikkeling is ' $n$ logiese uitvloeisel hiervan.

Mediagewoontes:

$$
\begin{aligned}
& \text { * Televisie word nie gereeld } \\
& \text { gekyk nie, maar indien } \\
& \text { daarna gekyk word, geniet } \\
& \text { sport voorkeur waarna ver- } \\
& \text { maaklikheidsprogramme, } \\
& \text { joernaalprogramme en } \\
& \text { nuusaktualiteite volg. } \\
& \text { * Inligting word meestal } \\
& \text { vanaf tydskrifte verkry } \\
& \text { maar soms ook vanaf die } \\
& \text { televisie en die radio. }
\end{aligned}
$$

* Selfverwesenliking en individuele ontwikkeling word hoog aangeslaan. * Finansiële sekuriteit en algemene sekuriteit is belangrik.

* Doelbereiking en die afdwing van respek word van waarde geskat.

\section{* Televisie word omtrent nooit gekyk nie, maar in- dien wel, is vermaaklik- heidsprogramme die mees waarskynlike, gevolg deur nuusaktualiteite en sport. \\ * Inligting word meestal van tydskrifte verkry maar soms ook vanaf televisie en die radio.}

\section{*'n Sterk behoefte aan finansiële- en algemene sekuriteit is aanwesig. \\ * Die afdwing van respek en individuele ontwikkeling word hoog aangeslaan. \\ * Ambisieus en geniet kom- petisie om bo uit te kom. Om die hoogste sport te bereik maak hulle op hulle- self staat.}

\section{* Televisie word nie baie gekyk nie, maar indien daar gekyk word, kry nuusaktualiteitsprogramme voorkeur. Laasgenoemde hang saam met die groep se politieke belangstelling. \\ * Radio word selde geluister en die meeste inligting word verkry vanaf tyd- skrifte en televisie.}

\author{
*'n Baie sterk behoefte aan \\ finansiële sekuriteit is aanwe- \\ sig. Onderliggend hieraan is \\ die behoefte aan selfver- \\ wesenliking en die behoefte \\ aan doelbereiking. \\ * Talente, harde werk en die eie \\ self word ingespan om met \\ doelbereiking mee te help. \\ * Opwinding, geluk en plesier \\ gee aan die groep ' $n$ beson- \\ derelewenslus wat tot uiting \\ kom in hul aktiewe en le- \\ wenslustige leefwyse. \\ * Geniet dit om televisie te \\ kyk alhoewel hulle nie elke \\ aand tyd voor die televisie \\ spandeer nie. Sport geniet \\ voorkeur waarna vermaak- \\ likheidsprogramme, \\ nuusaktualiteite en joer- \\ naalprogramme aan die \\ beurt kom. \\ * Inligting word hoofsaaklik \\ vanaf die televisie in- \\ gesamel gevolg deur die \\ gedrukte media en die \\ radio. \\ * Innergesentreerd met ' $n$ \\ telling van 76,86 .
} innergesentreerdheid. Indien in aanmerking geneem word dat die skeiding tussen die inner- en andergesentreerdheid 'n punt van 72 is, is die punt van 75,15 baie naby aan andergesentreerdheid.

Opsommend:

Groepering 1 is persone met min belangstelling in die kunste en ' $n$ matige belangstelling in sport. ' $n$ Uitstaande kenmerk is die matige motiveringskrag in alle fasette van hul lewe. Hulle lewe sonder enige uitstaande belangstelling in enigiets en is tevrede met basiese sekuriteit en matige sosialisering. Hierdie groep kan gevolglik as die apatiese groep getipeer word.
* Innergesentreerd met ' $n$

\section{telling van 82,60 . \\ Innergesentreerd met ' $n$ tipering van hierdie groep} individue (veral die sosiale onafhanklikheid) is in lyn hiermee.

Groepering 2 is die kunssinnige, sosiaal-onbetrokke boekwurms wat streef na verdere individuele ontwikkeling en verryking.
Groep 3 word gekenmerk deur sterk politieke belangstellings, sterk ambisies en 'n behoefte om vooruit te gaan. Die groep kan vervolgens as die polities-aktiewe, sosiaalgeïntegreerdes getipeer word.
Hierdie groep word gekenmerk deur hul veelsydigheid en aktiwiteit op alle gebiede. Hulle familievastheid en hul strewe na die hoogste sport maak hulle voorwaar die voortreflikes.
Die lewenstyltiperings wat in Tabel 2 aangetoon is, vervul die doelstelling van hierdie studie.

\section{SAMEVATTING EN GEVOLGTREKKINGS}

In hierdie studie is daarin geslaag om 'n lewenstylvraelys te ontwikkel. Hierdie vraelys is toegepas en vier lewenstylgroeperings is geïdentifiseer en suksesvol getipeer.

Toekomstige navorsing op hierdie terrein behoort gerig te wees op die verdere verfyning van die vraelys asook die verdere ontleding van die komplekse aard van lewenstyl. Aandag moet ook geskenk word aan die rol van persoonlikheid in lewenstyl en die koppeling van 'n individu se lewenstyl aan koopgedrag en mediaverbruik.

Die ontwikkeling van 'n Suid-Afrikaanse lewenstylvraelys kan steeds as dié ideaal gesien word vir enige studie op hierdie terrein.

\section{VERWYSINGS}

Boote, A.S. (1981). Market segmentation by personal values and salient product attributes. Journal of Advertising Research, 21(1), 29-35.

Bruce, F.C. (1988). Identifying psychological and socio-cultural characteristics of the coloured policy holder market segment in the Western Cape - a psychographic profile analysis in the life assurance industry. Ongepubliseerde M.Econ.-verhandeling, Universiteit van Stellenbosch, Stellenbosch.

Burns, A.C. \& Harrison, M.C. (1979). A test of reliability of psychographics. Journal of Marketing Research, 16, 32-38.

Churchill, G.A. (1979). A paradigm for developing better measures of marketing constructs. Journal of Marketing Research, 64-74.

Fox, R. (1989). Die tipering van verbruikerslewenstyle. Ongepubliseerde M.Econ.-verhandeling, Universiteit van Stellenbosch, Stellenbosch.

Kahle, L.R., Beatty, S.E. \& Homer, P. (1986). Alternative measurement approaches to consumer values. The list of values 
(LOV) and values and lifestyles (VALS). Journal of Consumer Research, 13, 405-409.

Kassarjian, W.M. (1962). A study of Riesman's theory of social character. Sociometry, 25, 213-230.

Kinnear, T.C. \& Taylor, J.R.(Jr.) (1976). Psychographics: some additional findings. Journal of Marketing Research, 13, 422-455.

Mehrotra, S. \& Wells, W.D. (1977). Psychographics and buyer behavior: theory and recent empirical findings. In Woodside, A.G., Sheth, J.N. \& Bennett, P.D. (Eds.), Consumer and industrial buying behavior. New York: North-Holland Inc.

Mitchell, A. (1984). Nine American lifestyles: values and societal change. The Futurist, 18(4), 4-14.

Roberts, M.L. \& Wortzel, L.H. (1979). New life-style determinants of woman's food shopping behavior. Journal of Marketing, 43, 28-39.
Tigert, D.J., Lanthrope, R. \& Bleeg, M. (1971). The fast food franchise: psychographic and demographic segmentation analysis. Journal of Retailing, 47(1), 81-90.

Wells, W.D. \& Tigert, D.J. (1971). Activities, interests and opinions. Journal of Advertising Research, 11(4), 27-35.

Wells, W.D. (1975). Psychografics: a critical review. Journal of Marketing Research, 12, 196-213.

Wells, W.D. (1985). Attitudes and behavior: lessons from the Needham lifestyle study. Journal of Advertising Research, 25(1), 40-44.

Zinkman, G.M. \& Shermohamad, A. (1986). Is outerdirectedness on the increase? An empirical test of Riesman's theory of social character. Journal of Consumer Research, 13, $127-130$. 